\title{
Regional differences in veins wall viscosity, compliance, energetics and damping: analysis of the pressure- diameter relationship during cyclical overloads
}

\author{
YANINA ZÓCALO ${ }^{1}$, DANIEL BIA ${ }^{1}$, SEBASTIÁN LLUBERAS $^{1}$ \\ and RICARDO L. ARMENTANO ${ }^{1,2}$ \\ ${ }^{1}$ Departamento de Fisiología, Facultad de Medicina. Universidad de la República, General Flores 2125 (P.C. \\ 11800), Montevideo, Uruguay. yana@fmed.edu.uy \\ ${ }^{2}$ Facultad de Ingeniería, Ciencias Exactas y Naturales, Universidad Favaloro. Solís 453, C1078AAI, Buenos \\ Aires, Argentina.armen@favaloro.edu.ar
}

\section{SUMMARY}

Background: The characterization of the dynamic process of veins walls is essential to understand venous functioning under normal and pathological conditions. However, little work has been done on dynamic venous properties. Aim: To characterize vein compliance $(C)$, viscosity $(\eta)$, peak-strain $\left(\mathrm{W}_{\mathrm{St}}\right)$ and dissipated $\left(\mathrm{W}_{\mathrm{D}}\right)$ energy, damping $(\xi)$, and their regional differences in order to evaluate their role in venous functioning during volume-pressure overloads. Methods: In a mock circulation, pressure $(\mathrm{P})$ and diameter $(\mathrm{D})$ of different veins (anterior cava, jugular and femoral; from 7 sheep), were registered during cyclical volume-pressure pulses. From the P-D relationship, $\mathrm{C}, \mathrm{W}_{\mathrm{St}}$ and $\xi$ (at low and high P-D levels), $\eta$ and $\mathrm{W}_{\mathrm{D}}$ were calculated. Results: For each vein there were P-dependent differences in biomechanical, energetics, and damping capability. There were regional-differences in $C, \eta, \mathrm{W}_{\mathrm{St}}$ and $\mathrm{W}_{\mathrm{D}}(\mathrm{p}<0.05)$, but not in $\xi$. Conclusion: The regional-dependent differences in dynamics and energetics, and regional-similitude in damping could be important to ensure venous functioning during acute overloads. The lower $\mathrm{C}$ and higher $\mathrm{W}_{\mathrm{St}}$ and $\mathrm{W}_{\mathrm{D}}$ found in back-limb veins (femoral), commonly submitted to high volume-pressure loads (i.e. during walking), could be considered relevant to ensure adequate venous system functionality and venous wall protection simultaneously.

Key terms: compliance, damping, energetic, vascular physiology, venous wall, viscosity.

\section{INTRODUCTION}

Although the venous system is considered a low pressure and pulsate system, it can suddenly become a high pressure and/or pulsatility system, in which veins support acute cyclical volume and/or pressure overloads. For example, when one is standing, 0.4-0.5 liters of blood is shifted out of the thorax into the veins of the legs, causing an abrupt increase in their pressure from approximately 2.67 to $13.33 \mathrm{kPa}$ (20 to $100 \mathrm{mmHg}$ ), and during running, pulsatility in leg veins is around $8.00-10.67 \mathrm{kPa}(60-80$ $\mathrm{mmHg}$ ) (Holtz, 1996). Under these conditions, compensatory mechanisms are triggered to ensure adequate venous return and to minimize venous overload (Holtz, 1996). Failure of compensatory mechanisms can lead to important haemostatic and/or venous wall alterations (Monos et al., 1995). Different characteristics of the venous system (i.e. venous valves, reflex vasoconstriction) have been related to the venous behavior during haemodynamic changes. Frequencydependent biomechanical properties (i.e. wall viscosity) can determine the venous response to acute haemodynamic overloads. However, dynamic vein wall properties and their potential role during pressure or volume overloads remain unknown (Bradley and Davis, 2003). Haemodynamic overloads

Corresponding Author: Prof. Daniel Bia Santana. Departamento de Fisiología. Facultad de Medicina. Universidad de la República. General Flores 2125. PC: 11800. Montevideo, Uruguay. Phone: (0598-2) 924-3414. Fax: (0598-2) 924-0395. E-mail:dbia@fmed.edu.uy 
could be deleterious, since pulsate and/or abrupt vessel stretch causes high-frequency mechanical vibrations or oscillations that could damage the vascular wall (Armentano et al., 2006). To reduce the vibrations, some structures are capable of damping (converting mechanical into thermal energy), which depends on the ratio between peak-strain energy and dissipated energy; which in turn is determined by the dynamic (visco-elastic) properties of the structure. We recently proposed a new approach to interpret the physiological role of arterial damping (Armentano et al., 2006), but venous damping capability remains unknown.

The structural diversity of veins could determine mechanical differences; therefore in order to characterize the dynamics of the venous it is necessary to analyse veins from different regions (Monos et al., 1995).

The aim of this research was to characterize visco-elastic properties, energetics and vein damping, and to evaluate their regional differences. We performed dynamic (rather than static) mechanical analysis, and studied venous segments (rather than the commonly used strips or rings) (Silver et al., 2003), to reproduce in vivo haemodynamic conditions, to preserve the shape and integrity of venous wall and quantify frequency-dependent biomechanical properties and not only static properties (Bia et al., 2005).

\section{METHODS}

The procedures were in accordance with the Guidelines for the Care and Use of Laboratory Animals published by the U.S. National Research Council (National Academy Press, Washington, D.C. 1996).

\section{Surgical preparation and segments obtained}

Seven adult sheep (body weight=25-35 kg) were anaesthetized (pentobarbital, 35 mgákg-1 intravenously) and the ventilation was maintained with mechanical assistance (Dragger SIMV Polyred 201, Madrid, Spain). Segments (6 cm-length) of the anterior cava (ACV), jugular (JV) and femoral (FV) veins were dissected and marked. After the sacrifice of the animals, the segments were excised, placed in Tyrode solution and sent for biomechanical testing.

\section{Biomechanical test}

The segments were mounted (at in vivo length) in a mock circulation organ chamber, and immersed in and perfused with Tyrode solution $\left(37^{\circ} \mathrm{C}\right.$, oxygenated, $\mathrm{pH}=7.4)$. The perfusion line consisted of polyethylene tubing in which Tyrode solution circulated, powered by a pneumatic pump (Jarvik 5, Kolff Medical Inc., Salt Lake City, Utah, USA). The mock circulation allowed for determining cyclical changes in vascular pressure (P) (Fig. 1A). Solid-state micro transducers $(1200 \mathrm{~Hz}$ frequency response, Konigsberg Instruments, Inc., Pasadena, CA, USA) were used to measure P. Ultrasonic crystals $(5 \mathrm{MHz})$ were sutured to the vessels to measure external diameter (D). The transit time of the ultrasonic signal $(1580 \mathrm{~m} / \mathrm{s})$ was converted into distance by means of a sonomicrometer $(1000 \mathrm{~Hz}$ frequency response, Triton Technology Inc. San Diego, CA, USA). The methodological approach has been used with in vivo and in vitro studies (Armentano et al., 2006; Bia et al., 2005; Zócalo et al., 2006).

The segments were allowed to stabilize for 10 minutes, under a dynamic state of volume and pressure changes. The segments were then submitted to cyclic changes (frequency $=1.8 \mathrm{~Hz}$ ) in $\mathrm{P}$, from 0 to $8.0 \mathrm{kPa}$ (0 to $60 \mathrm{mmHg}$ ) (Fig. 1A). The $\mathrm{P}$ and $\mathrm{D}$ signals were displayed in real time, and 20-30 consecutive cycles were sampled (sample frequency=200 Hz) and analyzed.

\section{Data Analysis}

The constructed P-D relationship showed a hysteretic area related to wall viscosity (Fig. 1B). To characterize wall viscoelasticity, a Kelvin-Voigt model (springdashpot) was used. According to the model, the $\mathrm{P}$ that developed in the wall $\left(\mathrm{P}_{\text {total }}\right)$ can be divided into elastic $\left(\mathrm{P}_{\text {elastic }}\right)$ and viscous ( $\mathrm{P}_{\text {viscous }}$ ) components (Bia et al., 2004; Bia et al., 2005): 


$$
\mathrm{P}_{\text {total }}=\mathrm{P}_{\text {elastic }}+\mathrm{P}_{\text {viscous }}
$$

The viscous component is proportional to the first derivative of the $\mathrm{D}$ in respect to time $(\mathrm{dD} / \mathrm{dt})$, such that:

$$
\mathrm{P}_{\text {elastic }}=\mathrm{P}_{\text {total }}-\eta \cdot \mathrm{dD} / \mathrm{dt}
$$

where $\eta$ is the viscous parameter. To characterize wall viscosity, the viscous term was subtracted from $\mathrm{P}_{\text {Total }}$, using the criterion of disappearance of the hysteresis loop (Bia et al., 2004). Increasing values of $\eta$ were given by visually inspecting the reduction of the hysteresis area (Fig. 1C). The $\eta$ value needed to reach a minimum (preserving the loop's clockwise course) was considered the venous wall viscous parameter (Bia et al., 2004). Two elastic parameters were then calculated as the slope of the purely elastic P-D relationship, at low $\left(\mathrm{E}_{\mathrm{LP}}\right.$, below P-D break-point) and high $\left(\mathrm{E}_{\mathrm{HP}}\right.$, above P-D break-point) P-D levels (Fig. 1C). The computed parameters were expressed as compliance $(\mathrm{C})$ at low $\left(\mathrm{C}_{\mathrm{LP}}=1 / \mathrm{E}_{\mathrm{LP}}\right)$ and high $\left(\mathrm{C}_{\mathrm{HP}}=1 / \mathrm{E}_{\mathrm{HP}}\right) \mathrm{P}-\mathrm{D}$ levels.

Viscous energy dissipation $\left(\mathrm{W}_{\mathrm{D}}\right)$ was $\omega \eta$

computed as: $\mathrm{W}_{\mathrm{D}}=\frac{}{\pi}$, where $\omega$ is angular frequency, $\omega \eta$ represents the loss modulus of the complex elastic modulus, and $\mathrm{A}$ is the normalized pulsate cross sectional area. The peak-strain energy $\left(\mathrm{W}_{\mathrm{St}}\right)$ stored in the wall and recovered without loss during $2 \mathrm{~A}$

unloading is: $\mathrm{W}_{\mathrm{St}}=\frac{}{\pi \mathrm{C}}$. We calculated the $\mathrm{W}_{\text {St }}$ for low and high P-D levels, $\mathrm{W}_{\text {St-LP }}$ and $\mathrm{W}_{\text {St-HP}}$, respectively. Wall damping ( $\xi$ ) was $W_{D}$

quantified as: $\xi \frac{}{W_{S t}}$, and calculated for low $\left(\xi_{\mathrm{LP}}\right)$ and high $\left(\xi_{\mathrm{HP}}\right)$ P-D levels (Armentano et al., 2006).

\section{Statistical analysis}

Values were expressed as mean \pm standard deviation $(\mathrm{MV} \pm \mathrm{SD})$. $\mathrm{T}$ tests were used to compare parameters calculated at low and high P-D levels. Multiple comparisons were performed using ANOVA followed by Bonferroni correction. A $\mathrm{p}<0.05$ was considered significant.

\section{RESULTS}

Physiological levels of venous $\mathrm{P}$ were satisfactorily simulated (Table I, Fig. 1A). Maximal and minimal $P$ showed no
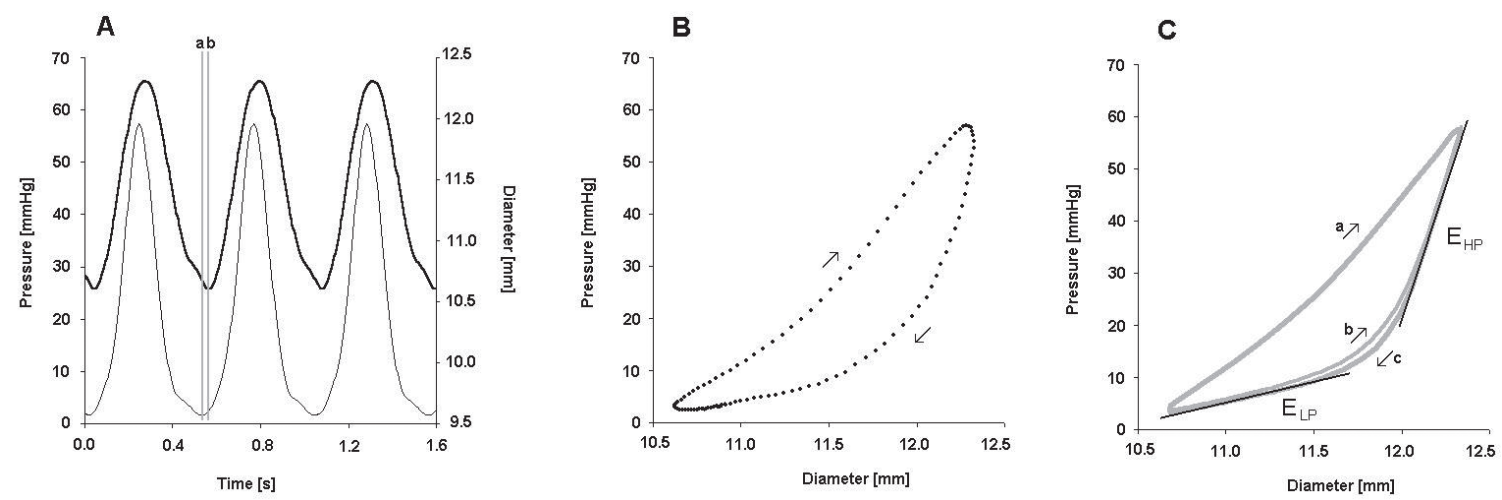

Figure 1: Temporal pressure and diameter signals and pressure-diameter loop. Part A: Pressure (thin line) and diameter (thick line) from a cava vein. The vertical lines $(a, b)$ indicate the delay between pressure and diameter signals. Part B: Pressure-diameter relationship obtained from the signals shown in A. Arrows indicate the ascending (loading) and descending (unloading) segments. Part $\boldsymbol{C}$ : Schema of the pressure-diameter relationship analysis. The a-c loop represents the original relationship, while the b-c loop represents the purely elastic relationship. Straight lines, using a curve-fitting program, were used to quantify the low-pressure $\left(\mathrm{E}_{\mathrm{LP}}\right)$ and high-pressure $\left(\mathrm{E}_{\mathrm{HP}}\right)$ slopes of the purely elastic relationship. 
differences among groups, enabling isobaric comparisons.

For each vein, $\mathrm{C}$ was lower at high $\mathrm{P}$ $(\mathrm{p}<0.05) \quad$ (Table II). There were differences in $\mathrm{C}$ among veins. The $\mathrm{ACV}$ showed the highest $\mathrm{C}$, both at low and high P-D levels $(\mathrm{p}<0.05)$. Viscosity was higher in the peripheral segments, particularly in the FV than in the ACV $(\mathrm{p}<0.05)($ Table II)

For all veins, $\mathrm{W}_{\mathrm{St}}$ was higher at high $\mathrm{P}$ D levels (Table III). When comparing veins, both, $\mathrm{W}_{\mathrm{St}}$ and $\mathrm{W}_{\mathrm{D}}$ were higher in the FV $(\mathrm{p}<0.05)$. $\xi$ was lower at high P-D levels and did not show differences among the studied segments (Table III).

\section{TABLE I}

Hemodynamic parameters

\begin{tabular}{lccc}
\hline & JUGULAR & ANTERIOR CAVA & FEMORAL \\
\hline Maximum P $(\mathrm{kPa})[\mathrm{mmhg}]$ & $6.93 \pm 0.66[52 \pm 5]$ & $7.06 \pm 0.66[53 \pm 5]$ & $7.33 \pm 0.93[55 \pm 7]$ \\
Minimum P $(\mathrm{kPa})[\mathrm{mmhg}]$ & $0.27 \pm 0.13[2 \pm 1]$ & $0.27 \pm 0.13[2 \pm 1]$ & $0.27 \pm 0.13[2 \pm 1]$ \\
Maximum D $(\mathrm{mm})$ & $10.4 \pm 3.1$ & $13.5 \pm 1.6^{\mathrm{a}}$ & $6.1 \pm 0.6^{\mathrm{ab}}$ \\
Minimum D $(\mathrm{mm})$ & $9.2 \pm 3.1$ & $10.9 \pm 1.6^{\mathrm{a}}$ & $5.4 \pm 0.4 \mathrm{ab}$ \\
\hline
\end{tabular}

Mean values \pm standard deviation. P: pressure; D: diameter. ANOVA followed by Bonferroni test: ${ }^{\mathrm{a}}, \mathrm{b}: \mathrm{p}<0.05$ with respect to to jugular and anterior cava, respectively.

TABLE II

Vein wall compliance and viscosity

\begin{tabular}{lccc}
\hline & JUGULAR & ANTERIOR CAVA & FEMORAL \\
\hline $\mathbf{C}_{\mathbf{L P}}\left(10^{-3} \mathrm{~m} / \mathrm{kPa}\right)$ & $2.03 \pm 0.23$ & $5.10 \pm 0.38^{\mathrm{a}}$ & $1.51 \pm 0.15^{\mathrm{ab}}$ \\
$\mathbf{C}_{\mathbf{H P}}\left(10^{-5} \mathrm{~m} / \mathrm{kPa}\right)$ & $1.73 \pm 0.23^{*}$ & $4.88 \pm 0.45^{* \mathrm{a}}$ & $1.35 \pm 0.15^{* \mathrm{ab}}$ \\
$\mathrm{h}(\mathrm{kPa} . \mathrm{s} / \mathrm{m})$ & $162.06 \pm 17.29$ & $53.20 \pm 7.87^{\mathrm{a}}$ & $203.49 \pm 30.59^{\mathrm{ab}}$ \\
\hline
\end{tabular}

Mean values \pm standard deviation. $\mathrm{C}_{\mathrm{LP}}$ and $\mathrm{C}_{\mathrm{HP}}$ : low and high-pressure compliance, respectively. $\mathrm{h}$ : viscous parameter. ANOVA followed by Bonferroni test: ${ }^{a, b}: \mathrm{p}<0.05$ with respect to jugular and anterior cava, respectively. ${ }^{*}$ p<0.05 with respect to the same parameter and vein, at low pressure-diameter level.

TABLE III

Vein wall energetics and damping parameters

\begin{tabular}{lccc}
\hline & JUGULAR & ANTERIOR CAVA & FEMORAL \\
\hline $\mathbf{W}_{\mathbf{D}}\left(\mathrm{J} / \mathrm{m}^{2}\right)$ & $134.54 \pm 11.19$ & $108.83 \pm 10.90^{\mathrm{a}}$ & $202.23 \pm 20.65^{\mathrm{ab}}$ \\
$\mathbf{W}_{\text {St.LP }}\left(10^{2} \mathrm{~J} / \mathrm{m}^{2}\right)$ & $0.48 \pm 0.02$ & $0.47 \pm 0.04$ & $0.78 \pm 0.03^{\mathrm{ab}}$ \\
$\mathbf{W}_{\text {St.HP }}\left(10^{2} \mathrm{~J} / \mathrm{m}^{2}\right)$ & $29.31 \pm 1.82^{*}$ & $23.62 \pm 1.70 * \mathrm{a}$ & $43.22 \pm 2.73^{* \mathrm{ab}}$ \\
$\mathbf{X}_{\mathbf{L P}}\left(10^{-1}\right)$ & $26.61 \pm 4.42$ & $23.83 \pm 2.72$ & $26.04 \pm 2.53$ \\
$\mathbf{X}_{\mathbf{H P}}\left(10^{-1}\right)$ & $0.47 \pm 0.04^{*}$ & $0.44 \pm 0.03^{*}$ & $0.47 \pm 0.03^{*}$
\end{tabular}

Mean values \pm standard deviation. $\mathrm{W}_{\mathrm{D}}$ : energy dissipation. $\mathrm{W}_{\mathrm{St}-\mathrm{LP}}$ and $\mathrm{W}_{\mathrm{St}-\mathrm{LP}}$ : storage peak-strain energy at low and high pressure-diameter levels, respectively. $\mathrm{x}_{\mathrm{LP}}$ and $\mathrm{x}_{\mathrm{HP}}$ : wall-damping capability at low and high pressure-diameter levels, respectively. ANOVA followed by Bonferroni test: a b: $\mathrm{p}<0.05$ with respect to jugular and anterior cava, respectively. $* \mathrm{p}<0.05$ with respect to the same parameter and vein, at low pressurediameter level. 


\section{DISCUSSION}

This is the first work to characterize vein viscosity, energetics and damping, and the regional differences among veins during physiological conditions.

The main findings were that veins showed regional differences in viscoelasticity and energetics, but that damping was similar.

\section{Venous compliance and peak strain energy}

Our data evidenced the recognized nonlinearity (P-dependence) of veins compliance (Freeman et al., 2002), also found in $\mathrm{W}_{\mathrm{St}}$. At low $\mathrm{P}$, the $\mathrm{P}-\mathrm{D}$ slope is low, meaning that a large change in $\mathrm{D}$ (or volume) comes with only a small $\mathrm{P}$ change. Consequently, compliance and pulsate area are high. At higher $\mathrm{P}$, the $\mathrm{P}-\mathrm{D}$ relationship slope is steeper, the venous compliance and pulsate area are lower and their relationship determines an increase in $\mathrm{W}_{\mathrm{St}}$ (Tables II and III).

The P-D relationship shape could represent a functional adaptation that allows veins to respond adequately to changes in load. During an acute volume load the initial high compliance would ensure adequate cardiac filling, with reduced right atrium pressures. On the other hand, the low-compliance phase prevents vascular over-distension and the reduction in central P (i.e. extreme venous pooling during postural changes) (Freeman et al., 2002). Moreover, as was suggested, without the low-compliance portion of the P-D curve, the upright posture without hypotension would be impossible (Olsen et al., 2000). These veins characteristics enable the venous system to act as a "haemodynamic buffer", contributing to maintain adequate central $\mathrm{P}$ levels, venous return and cardiac output (Monos et al., 1995, Freeman et al., 2002).

When comparing veins from different regions, we found differences in compliance and $\mathrm{W}_{\mathrm{St}}$ at both low and high $\mathrm{P}$ levels (Table II). The ACV (the central vein) showed the highest compliance, while the FV was the stiffest vein (least compliance) and showed the highest $\mathrm{W}_{\mathrm{St}}$.
These results agree with the regional differences recently found where veins were characterized under arterial haemodynamic conditions (Zócalo et al., 2006).

It is noteworthy that regional differences in compliance and $\mathrm{W}_{\mathrm{St}}$ could not only be ascribed to geometrical differences, but also, as our results suggest, to the intrinsic biomechanical properties of the veins. In this respect, the JV and ACV showed similar $\mathrm{W}_{\mathrm{St}}$, despite their differences in diameter (or cross-sectional area). The regional-differences in venous compliance and $\mathrm{W}_{\mathrm{St}}$ could be important in haemodynamic control mechanisms. For example, an abrupt change from the supine to the orthostatic position promotes the movement of blood from central (i.e. thoracic) to peripheral (i.e. limbs) veins. This fluid shift reduces central blood volume and cardiac filling, and could determine a transient compromise in arterial blood pressure, representing cardiovascular stress (Olsen et al., 2000). However, if fluid shifts into the peripheral veins are minimized, due to the relative stiffness of the peripheral veins, cardiovascular disturbances can be reduced. Hence, the differences in compliance among veins would be important in determining cardiovascular disturbances as the result of posture changes.

\section{Vein wall viscosity and energy dissipation capability}

Energy dissipation due to viscous properties allows veins to resist deformation with a frequency or velocity-dependent mechanism (Silver et al., 2003). Although viscous behavior of veins was identified a long time ago (Alexander, 1963; Anliker et al., 1971; Nippa et al., 1971), no works have quantified viscosity and/or evaluated its meaning in relation to the physiology of veins. In this work, we postulate that this apparent "energetic disadvantage" (energy loss) could contribute to damping, during haemodynamic overloads (Armentano et al., 2006).

Vein viscosity was higher in the peripheral segments (Table II). The 
differences in viscosity could not be determined by the experimental conditions, since they were the same for all the segments, but they could depend on the structural differences among the veins. The higher viscosity in the peripheral segments could be important in the response to acute overloads and in haemodynamic control. The slow D change in peripheral veins could reduce acute volume variations, and hence, the fall in the cardiac filling. Moreover, since this mechanism depends on the intrinsic properties of the vein wall, it could be a first response to avoid haemodynamic disturbances related to postural changes.

Wall viscosity determines $\mathrm{W}_{\mathrm{D}}$, so its contribution to veins physiology and wall protection should be analyzed in energetic terms. Up to now, veins were not considered as structures with a high capacity to dissipate energy during physiological conditions. However, this work evidenced that veins have a highenergy dissipation capability. This could be a functional advantage that allows the venous system to bear and respond adequately to acute overloads. During postural changes, veins work conditions are rapidly modified and $W_{D}$ could be important in preventing wall damage during load changes. Additionally, high $\mathrm{W}_{\mathrm{D}}$ in peripheral veins could determine a rapid attenuation of waves that travel towards the heart (i.e. during walking).

\section{Vein wall damping capability}

The reduction of $\xi$ at high $\mathrm{P}$ levels (Table III) suggests that the passive venous capability to protect itself is reduced during volume and/or $\mathrm{P}$ overloads. In previous works, similar results were found when evaluating arteries submitted to passive acute volume and/or P overloads (Bia et al., 2004). But, it remains to be elucidated, if the veins' smooth muscle regulates the $\mathrm{x}$, keeping the wall protected during haemodynamic overloads, as has been described with arteries (Armentano et al., 2006).

Despite the regional differences in $\mathrm{W}_{\mathrm{St}}$ and $\mathrm{W}_{\mathrm{D}}$, there were no differences in veins $\xi$. Hence, to withstand dissimilar loads, veins have different biomechanical and energetic properties, but the $\mathrm{x}$ capability would be a constant in the venous system, as we proposed for arteries (Bia et al., 2005). (Table III).

\section{Final remarks}

In this work the biomechanical behavior of different veins was evaluated, analyzing the instantaneous P-D relationship. The veins' dynamic biomechanical properties, energetics and damping were characterized and compared. We found regional differences in the biomechanical parameters and energetics, but damping was similar among veins.

Considering our results, it could be a physiological mechanism that depend on veins wall dynamics and contributes to the veins' response to haemodynamic changes, keeping the wall protected against highfrequency vibrations. Since the proposed mechanism would depend on the intrinsic properties of the venous wall, it could be considered a continuous regulator of the venous return and a first response to haemodynamic disturbances.

\section{ACKNOWLEDGMENTS}

This work was performed under a cooperation agreement between the Universidad de la República and the Universidad Favaloro, and was partially supported by PE.DE.CI.BA (Uruguay). The authors acknowledge the contribution of Elbio Agote.

\section{REFERENCES}

ALEXANDER RS (1963) The peripheral venous system. HAMILTON WF, DOW P (eds), Handbook of physiology, Baltimore, Maryland: Waverly Press Inc, pp: 1075-1098

ANLIKER M, YATES WG, OGDEN E (1971) Transmission of small pressure waves in the canine vena cava. Am J Physiol 221: 644-51.

ARMENTANO RL, BARRA JG, SANTANA DB, PESSANA FM, GRAF S, CRAIEM D, BRANDANI LM, BAGLIVO HP, SANCHEZ RA (2006) Smart damping modulation of carotid wall energetics in 
human hypertension: effects of angiotensin-converting enzyme inhibition. Hypertension 47: 384-90.

BIA D, ARMENTANO R, CRAIEM D, GRIGNOLA J, GINES F, SIMON A, LEVENSON J (2004) Smooth muscle role on pulmonary arterial function during acute pulmonary hypertension in sheep. Acta Physiol Scand 181: 359-66.

BIA D, AGUIRRE I, ZÓCALO Y, DEVERA L, CABRERA FISCHER E, ARMENTANO R (2005) Regional differences in viscosity, elasticity and wall buffering function in systemic arteries: pulse wave analysis of the arterial pressure-diameter relationship. Rev Esp Cardiol 58: 167-74

BRADLEY JG, DAVIS KA (2003) Orthostatic hypotension. Am Fam Physician 68: 2393-8.

FREEMAN R, LIROFONIS V, FARQUHAR WB, RISK M (2002) Limb venous compliance in patients with idiopathic orthostatic intolerance and postural tachycardia. J Appl Physiol 93: 636-44.

HOLTZ J 1996): Peripheral circulation: Fundamental concepts, comparative aspects of control in specific vascular sections, and lymph flow. GREGER R,
WINDHORST U. (eds.), Comprehensive human physyiology. From cellular mechanisms to integration. Berlin Heidelberg, Springer-Verlag, pp: 1865-1915.

MONOS E, BERCZI V, NADASY G (1995) Local control of veins: biomechanical, metabolic, and humoral aspects. Physiol Rev 75: 611-66.

NIPPA JH, ALEXANDER RH, FOLSE R (1971) Pulse wave velocity in human veins. J Appl Physiol 30, 55863

OLSEN H, VERNERSSON E, LANNE T (2000) Cardiovascular response to acute hypovolemia in relation to age. Implications for orthostasis and hemorrhage. Am J Physiol Heart Circ Physiol 278: H222-32.

SILVER FH, SNOWHILL PB, FORAN DJ (2003) Mechanical behavior of vessel wall: a comparative study of aorta, vena cava, and carotid artery. Ann Biomed Eng 31: 793-803.

ZÓCALO Y, PESSANA F, BIA D, ARMENTANO R (2006) Regional differences in vein wall dynamics under arterial haemodynamic conditions. Artif Organs 30: $265-75$ 


